\title{
Avaliação de genótipos de caupi sob salinidade ${ }^{1}$
}

\author{
José P. Dantas ${ }^{2}$, Francisco J. L. Marinho ${ }^{3}$, Magna M. M. Ferreira ${ }^{4}$, Maria do S. N. Amorim ${ }^{5}$, \\ 1 Trabalho financiado pelo CNPq - Projeto Nordeste de Pesquisa e Pós-Graduação \\ 2 DEQ/CCT/UEPB. Campina Grande, PB. Fone: (83) 341-1961. E-mail: gpcnpq@terra.com.br (Foto) \\ 4 UEPB, Bolsista DCR/CNPq. E-mail: magna.m.m.ferreira@bol.com.br \\ 5 UEPB, Bolsista AT/CNPq. E-mail: gpcnpq@terra.com.br \\ 6 UEPB, Bolsista IC/CNPq. E-mail: gpenpq@terra.com.br
} Sílvia I. de O. Andrade ${ }^{6} \&$ Adriana L. de Sales ${ }^{6}$

3 EAAC/UEPB. E-mail: kalinde@globo.com

Protocolo $179-27 / 12 / 2001$

\begin{abstract}
Resumo: Foram conduzidos ensaios em abrigo telado de vegetação com cobertura de telha de fibra de vidro com o objetivo de se avaliar a tolerância de 50 genótipos de caupi sob salinidade. Os tratamentos de salinidade aplicados no solo, em termos de condutividade elétrica do extrato de saturação (CE), foram: $\mathrm{CE}_{1}-0,3, \mathrm{CE}_{2}-3,0, \mathrm{CE}_{3}-6,0, \mathrm{CE}_{4}-9,0$ e $\mathrm{CE}_{5}-12,0$ dS m-1. Os genótipos foram classificados para tolerância à salinidade com base na redução percentual do peso de matéria seca da parte aérea. No tratamento $\mathrm{CE}_{2}, 36$ genótipos foram tolerantes (T), 12 moderadamente tolerantes (MT) e 2 moderadamente sensíveis (MS); no tratamento $\mathrm{CE}_{3}$, 3 foram $\mathrm{T}, 14 \mathrm{MT}, 30 \mathrm{MS}$ e 3 sensíveis (S); no tratamento $\mathrm{CE}_{4}$, um foi MS e $49 \mathrm{~S}$ e, no tratamento $\mathrm{CE}_{5}$, todos foram S. O teor de proteína nos grãos foi influenciado pela salinidade e variou de genótipo para genótipo.
\end{abstract}

Palavras-chave: Vigna unguiculata, estresse salino, proteína

\section{Assessment of cowpea genotypes under salinity}

\begin{abstract}
To assess the tolerance of 50 cowpea genotypes under salinity, experiments were conducted in greenhouse covered with fiberglass sheets. The salinity treatments applied in terms of electrical conductivity of saturation extract of soil (EC) were $\mathrm{EC}_{1}-0.3 ; \mathrm{EC}_{2}-3.0 ; \mathrm{EC}_{3}-6.0$; $\mathrm{EC}_{4}-9.0$ and $\mathrm{EC}_{5}-12.0 \mathrm{dS} \mathrm{m}{ }^{-1}$. The genotypes were classified for the salinity tolerance on the basis of the reduction in dry weight (\%) of shoot. Under $\mathrm{EC}_{2}, 36$ genotypes were tolerant (T), 12 moderately tolerant (MT) and 2 moderately susceptible (MS); under $\mathrm{EC}_{3}, 3$ were T, $14 \mathrm{MT}, 30$ $\mathrm{MS}$ and 3 susceptible (S); under $\mathrm{EC}_{4}$, one was $\mathrm{MS}$ and $49 \mathrm{~S}$ and under $\mathrm{EC}_{5}$, all were $\mathrm{S}$. The protein content of seed was influenced by salinity and varied with the genotype.
\end{abstract}

Key words: Vigna unguiculata, salinity stress, protein

\section{INTRODUÇÃO}

A região Nordeste do Brasil abrange uma área de 1.600 .000 $\mathrm{km}^{2}$, dos quais $1.500 .000 \mathrm{~km}^{2}$ são caracterizados como de insuficiência hídrica, constituindo o "polígono das secas". Nessa região, a irrigação passa a assumir papel fundamental no desenvolvimento da agricultura. Gheyi et al. (1991) relatam que, de acordo com estimativas do Programa Nacional de Irrigação (PRONI), há, no Nordeste, cerca de 6.000 .000 ha de solos potencialmente irrigáveis.

A prática da irrigação, entretanto, deve ser usada de maneira racional, uma vez que as condições de clima do "polígono das secas" (altas temperaturas, baixa pluviosidade e intensa evaporação) e os elevados teores de sais na água de irrigação, associados à falta ou deficiência de drenagem, têm ocasionado crescentes problemas de salinidade dos solos reduzindo, de maneira acentuada, o crescimento e a produtividade das culturas desenvolvidas na região. Estima-se que, na região semi-árida, $25 \%$ dos solos irrigados estão afetados por diferentes graus de salinidade. Com a incorporação de novas áreas irrigadas, esse problema vem aumentando a cada ano (Pereira et al., 1985; Santos et al., 1990).

O caupi é uma leguminosa herbácea cujos grãos são de alto valor biológico alimentar, devido ao seu elevado teor protéico, sendo cultivado principalmente por agricultores familiares, quer como cultura de subsistência ou comercial nas regiões Norte e Nordeste do Brasil, adaptando-se bem às adversidades climáticas e edáficas, em virtude das suas características de rusticidade e precocidade. 
Nas áreas urbanas não metropolitanas do Nordeste, o caupi contribui com $41 \%$ do feijão consumido, constituindo-se no alimento básico para a população, exercendo a função de supridor das necessidades alimentares das camadas carentes. Suas propriedades nutricionais, relativamente superiores às do feijão comum, e o baixo custo de produção, fazem com que esta cultura seja considerada extremamente importante em termos sociais e econômicos, para a região (Araújo \& Watt, 1988).

Com o aumento dos problemas de salinização dos solos no Nordeste, em virtude do aumento da área utilizada com culturas irrigadas, o sucesso da atividade agrícola pode ser alcançado através da adoção de práticas de manejo de solo, capazes de reduzir a salinidade, e da seleção de genótipos tolerantes ao estresse salino. Como o primeiro procedimento é dispendioso, demorado e, às vezes, impraticável, a segunda opção apresentase promissora (Araújo, 1994).

Ayers \& Westcot (1991) consideram o caupi moderadamente tolerante à salinidade, com salinidade limiar em torno de $4,9 \mathrm{dS} \mathrm{m}^{-1}$, não apresentando, no entanto, dados a nível de genótipos.

Segundo Araújo \& Watt (1988) os bancos de germoplasma de caupi no Brasil se iniciaram com o Programa Nacional de Melhoramento, em 1977, o que contribuiu para o aumento da disponibilidade de genótipos para utilização em programas de seleção e adaptação dessa cultura ao estresse salino.

Pelo exposto, o presente trabalho teve como objetivo avaliar a tolerância ao estresse salino no solo de 50 genótipos de caupi, identificando possíveis influências na produção de biomassa e no teor de proteína dos grãos.

\section{MATERIAL E MÉTODOS}

Os ensaios foram conduzidos em abrigo telado de vegetação com cobertura de telha de fibra de vidro, no município de Lagoa Seca, PB, de janeiro a julho de 2001. Os genótipos de feijão caupi [(Vigna unguiculata (L.) Walp] submetidos a experimentação, encontram-se na Tabela 1.

O material do solo utilizado como substrato foi um Neossolo Regolílitico coletado ao lado do Lar do Garoto Padre Otávio, no município de Lagoa Seca, PB.

As metodologias utilizadas na análise do solo foram os métodos analíticos constantes no Manual de Análises Químicas e Físicas (EMBRAPA, 1997). O pH foi extremamente ácido; o teor de alumínio trocável alto e de $\mathrm{Ca}$ e $\mathrm{Mg}$ baixos, indicando a necessidade de calagem (Tabela 2). A dose de calcário aplicada por hectare e calculada por vaso de PVC de $10,00 \mathrm{dm}^{3}$ de solo, foi obtida pela Eq. (1):

$$
\mathrm{NC}=\left[20-\left(\mathrm{mmol}_{\mathrm{c}} \mathrm{Ca}+\mathrm{mmol}_{\mathrm{c}} \mathrm{Mg}\right] \times 2 \mathrm{x} / 10\right.
$$

em que:

$\mathrm{NC}$ - necessidade de calcário em $\mathrm{Mg} \mathrm{ha}^{-1}$

f $\quad$ - fator de calagem do solo $=100 /[\mathrm{PRNT}$ (calcário)]

PRNT(calcário) - poder relativo de neutralização total do calcário, que foi igual a $65 \%$.

Calculada a dose de calcário por hectare, constatou-se um valor de 4,0 $\mathrm{Mg} \mathrm{ha}^{-1}$ ou 18,0 $\mathrm{g}_{\text {vaso }}^{-1}$ contendo $9 \mathrm{dm}^{3}$ de solo,
Tabela 1. Genótipos de feijão caupi [(Vigna unguiculata (L.) Walp] submetidos a experimentação

\begin{tabular}{|c|c|}
\hline 01. Canapu Amarelo & 26. TE $97-299$ G12 \\
\hline 02. Galanjão Vermelho & 27. TE $97-299$ G13 \\
\hline 03. Manteiga & 28. TE-299 G15 \\
\hline 04. Ligeirinho & 29. TE-299 G16 \\
\hline 05. Flor Branca & 30. TE-299 G22 \\
\hline 06. Cabecinha & 31. TE-299 G26 \\
\hline 07. IPA 201 & 32. TE $97-365$ G1 \\
\hline 08. IPA 202 & 33. TE $97-299$ G27 \\
\hline 09. IPA 204 & 34. TE 97-304 G4 \\
\hline 10. IPA 205 & 35. TE 97-304 G6 \\
\hline 11. IPA 206 & 36. TE 97-304 G7 \\
\hline 12. Sempre Verde & 37. TE 97-304 G1 \\
\hline 13. Costela de Vaca & 38. TE 97-309 G3 \\
\hline 14. Parambu & 39. TE $97-367 \mathrm{G} 1$ \\
\hline 15. EPACE 10 & 40. TE-367 G4-2 \\
\hline 16. Corujinha & 41. TE-430 G13 \\
\hline 17. Diamante & 42. TE $97-309$ G14 \\
\hline 18. Canapu & 43. TE $97-433$ G4 \\
\hline 19. BR 17-Gurgéia & 44. TE $97-432$ G5 \\
\hline 20. TE 97-299 G1 & 45. TE $97-432 \mathrm{G} 4$ \\
\hline 21. TE 97-299 G3 & 46. TE $97-365 \mathrm{G} 3$ \\
\hline 22. TE 97-304 G2 & 47. TE $97-433$ G5 \\
\hline 23. TE 97-304 G3 & 48. TE $97-319 \mathrm{G} 3$ \\
\hline 24. TE $97-303$ G5 & 49. TE $97-319$ G9 \\
\hline 25. TE 97-303 G6 & 50. TE $97-433$ G10 \\
\hline
\end{tabular}

Tabela 2. Propriedades químicas e físicas do solo utilizado no experimento

\begin{tabular}{|c|c|}
\hline pH em KCl 1,0 M & 3,9 \\
\hline Matéria Orgância $\left(\mathrm{g} \mathrm{dm}^{-3}\right)$ & 13,0 \\
\hline Fosfato $\left(\mathrm{mg} \mathrm{dm}^{-3}\right)$ & 3,0 \\
\hline Sulfato $\left(\mathrm{mg} \mathrm{dm}^{-3}\right)$ & 18,0 \\
\hline Potássio $\left(\mathrm{mmol}_{\mathrm{c}} \mathrm{dm}^{-3}\right)$ & 1,2 \\
\hline Cálcio $\left(\mathrm{mmol}_{\mathrm{c}} \mathrm{dm}^{-3}\right)$ & 5,0 \\
\hline Magnésio $\left(\mathrm{mmol}_{\mathrm{c}} \mathrm{dm}^{-3}\right)$ & 2,0 \\
\hline Alumínio $\left(\mathrm{mmol}_{\mathrm{c}} \mathrm{dm}^{-3}\right)$ & 7,0 \\
\hline Hidrogênio + Alumínio $\left(\mathrm{mmol}_{\mathrm{c}} \mathrm{dm}^{-3}\right)$ & 25,0 \\
\hline Soma de bases $\left(\mathrm{mmol}_{\mathrm{c}} \mathrm{dm}^{-3}\right)$ & 8,2 \\
\hline Capacidade de troca de cátions $\left(\mathrm{mmol}_{\mathrm{c}} \mathrm{dm}^{-3}\right)$ & 33,2 \\
\hline Percentagem de saturação de bases trocáveis $(\%)$ & 25,46 \\
\hline $\mathrm{B}\left(\mathrm{g} \mathrm{dm}^{-3}\right)$ & 0,1 \\
\hline $\mathrm{Cu}^{++}\left(\mathrm{mg} \mathrm{dm}^{-3}\right)$ & 0,1 \\
\hline $\mathrm{Fé}^{+++}\left(\mathrm{mg} \mathrm{dm}^{-3}\right)$ & 54,0 \\
\hline $\mathrm{Mn}^{++}\left(\mathrm{mg} \mathrm{dm}^{-3}\right)$ & 1,2 \\
\hline $\mathrm{Zn}^{++}\left(\mathrm{mg} \mathrm{dm}^{-3}\right)$ & 0,3 \\
\hline Textura & Arenosa \\
\hline Capacidade de Campo $\left(\mathrm{g} \mathrm{kg}^{-1}\right)$ & 97,3 \\
\hline Ponto de Murcha Permanente $\left(\mathrm{g} \mathrm{kg}^{-1}\right)$ & 21,4 \\
\hline Ponto de Saturação Máxima $\left(\mathrm{g} \mathrm{kg}^{-1}\right)$ & 200,0 \\
\hline Condutividade elétrica do extrato de saturação $\left(\mathrm{dS} \mathrm{m}^{-1}\right)$ & 0,3 \\
\hline
\end{tabular}

considerando-se a área de um hectare com $20 \mathrm{~cm}$ de profundidade.

O calcário foi homogeneizado aos $9,0 \mathrm{dm}^{3}$ de solo, por vaso, e mantido durante $30 \mathrm{~d}$ em incubação na umidade correspondente à capacidade de campo, ficando os vasos cobertos com lona preta à sombra, para evitar evaporação. Transcorridos os 30 d de incubação, o solo, nos vasos, foi colocado para secar, partindo-se para a indução dos tratamentos.

Os tratamentos submetidos a experimentação por genótipo de feijão caupi, constaram de cinco níveis de salinidade, dados pela condutividade elétrica no extrato de saturação do solo 
(CE): 0,3; 3,0; 6,0; 9,0 e $12 \mathrm{dS} \mathrm{m}^{-1}$. Estas CEs foram preparadas a partir de diluição de efluente de dessalinizador com condutividade elétrica de $28,30 \mathrm{dS} \mathrm{m}^{-1}$. O quantitativo do efluente diluído na $\mathrm{CE}$ desejada foi calculado com base no ponto de saturação máxima do solo, dado pela análise física do mesmo, utilizando-se adequado volume de água. O volume exato do efluente que conferisse o nível foi estabelecido a partir de uma curva de calibração entre o volume do efluente e o nível de $\mathrm{CE}$ do solo. Cada tratamento, com 4 repetições, foi acondicionado em vaso de PVC com capacidade de $10,0 \mathrm{dm}^{3}$ de solo. O delineamento experimental foi o inteiramente casualizado.

Após a aplicação da solução salina no solo, por vaso, conforme volume estimado, objetivando-se a indução dos níveis de salinidade, o mesmo foi posto a secar até a obtenção de terra fina seca ao ar; após este procedimento, o solo foi homogeneizado e irrigado com água de baixa salinidade $\left(0,1 \mathrm{dS} \mathrm{m}^{-1}\right)$ ficando a $90 \%$ da capacidade de campo. Por razão do solo apresentar limitação em sua fertilidade, elevaramse os teores de N, P, K, Ca, Mg, S, B, Cu, Mn, Mo e Zn a valores de 200,0;200,0;200,0; 50,0;25,0; 50,0; 1,0;2,0;2,0;0,5 e $5,0 \mathrm{mg} \mathrm{dm}^{-3}$, respectivamente, com fertilizantes minerais. Transcorridos cinco dias da adubação e se mantendo o solo sempre na capacidade de campo, procedeu-se à semeadura, colocando-se 10 sementes por vaso, dos genótipos de feijão caupi que, após germinarem, foram reduzidas a três plantas por vaso, 15 dias após o plantio, onde permaneceram até a floração plena, quando se deixou uma planta, por vaso, até a colheita total das vagens. Durante o período experimental, a umidade do solo foi mantida acima de $80 \%$ da capacidade de campo.

Com o objetivo de se determinar o peso de matéria seca da parte aérea (ramos e folhas) foram tomadas, na época da floração, duas plantas por repetição, por tratamento, para cada genótipo, que foram acondicionadas em sacos de papel e secadas em estufa com circulação forçada de ar, a temperatura de $55{ }^{\circ} \mathrm{C}$, até peso constante. Para a análise estatística dos dados, utilizou-se o programa computacional ESTAT, da Faculdade de Ciências Agrárias e Veterinárias da Universidade Estadual Paulista, Jaboticabal, São Paulo.

Obteve-se a curva de regressão polinomial relacionando-se os níveis de salinidade aos valores médios do peso de matéria seca da parte aérea, o que permitiu a determinação dos efeitos da salinidade sobre os diferentes genótipos. As equações foram escolhidas com base na sua significância e no valor do coeficiente de determinação $\left(\mathrm{R}^{2}\right)$. Escolheu-se a regressão quadrática por se entender que os modelos cúbicos não explicam adequadamente os fenômenos biológicos. Foram observadas as perdas percentuais em relação ao controle (redução em \%) em todos os genótipos, as quais foram utilizadas como indexadores para comparar a tolerância dos diferentes materiais genéticos, classificando-os de acordo com a Tabela 3.

A Redução da Produção (RP) em \% foi obtida pela equação:

$$
\mathrm{RP}=\frac{\mathrm{PTNS}-\mathrm{PTS}}{\mathrm{PTNS}} 100
$$

em que:

PTNS - produção do tratamento que não recebeu salinização (salinidade natural do solo)
PTS - produção do tratamento que recebeu salinização (por nível)

Tabela 3. Classificação dos genótipos de feijão caupi quanto à tolerância ao estresse salino, tomando-se como referência o peso de matéria seca da parte aérea na época da floração

\begin{tabular}{cc} 
Redução da Produção (\%) & Classificação \\
$0-20$ & Tolerante (T) \\
$20-40$ & Moderadamente Tolerante (MT) \\
$40-60$ & Moderadamente Sensível (MS) \\
$>60$ & Sensível (S) \\
\hline
\end{tabular}

Com base na classificação da Tabela 3, escolheram-se 14 genótipos de feijão caupi para a determinação do teor de proteína nos grãos, na seguinte ordem: 2 genótipos tolerantes em $\mathrm{CE}_{2}\left(3,0 \mathrm{dS} \mathrm{m}^{-1}\right)$ e $\mathrm{CE}_{3}\left(6,0 \mathrm{dS} \mathrm{m}^{-1}\right)$ (IPA 201 e EPACE 10), 5 tolerantes em $\mathrm{CE}_{2}\left(3,0 \mathrm{dS} \mathrm{m}^{-1}\right)$ e moderadamente tolerantes em $\mathrm{CE}_{3}\left(6,0 \mathrm{dSm}^{-1}\right)($ Cabecinha, TE 97-304 G3, TE-299 G22, TE-299 G26 e IPA 205), 3 tolerantes em $\mathrm{CE}_{2}\left(3,0 \mathrm{dS} \mathrm{m}^{-1}\right)$ e moderadamente sensíveis em $\mathrm{CE}_{3}\left(6,0 \mathrm{dS} \mathrm{m}^{-1}\right)$ (IPA 202, Canapu e Sempre Verde) e 4 moderadamente tolerantes em $\mathrm{CE}_{2}\left(3,0 \mathrm{dS} \mathrm{m}^{-1}\right)$ e moderadamente sensíveis em $\mathrm{CE}_{3}\left(6,0 \mathrm{dS} \mathrm{m}^{-1}\right)$ (Canapu Amarelo, TE 97-299 G12, TE 97-299 G13 e TE 97-304 G7). A planta unitária que ficou por vaso foi deixada até o estádio de produção de vagem seca. Depois de colhidos os grãos, estes foram colocados em sacos de papel e secados em estufa com circulação forçada de ar, na temperatura de $50{ }^{\circ} \mathrm{C}$. Após moídos em moinho de bola, os grãos foram analisados para proteína $(\% \mathrm{~N}$ total x 6,25), utilizando-se o método semi-micro Kjeldahl, descrito por Malavolta et al. (1989).

\section{RESULTADOS E DISCUSSÃO}

Os resultados referentes à produção de matéria seca dos 50 genótipos de caupi submetidos a níveis crescentes de salinidade no solo, estão apresentados na Tabela 4.

Enquanto os genótipos Parambu, IPA 201 e EPACE 10 foram os únicos tolerantes aos tratamentos $\mathrm{CE}_{2}$ e $\mathrm{CE}_{3}$, somente TE 97-303 G5 apresentou sensibilidade moderada ao tratamento $\mathrm{CE}_{4}$. Com sensibilidade já no tratamento $\mathrm{CE}_{3} \mathrm{de}$ salinidade no solo, destacaram-se os genótipos TE 97-367 G1, TE 97-309 G14 e TE 97-432 G5. Todos os genótipos foram sensíveis ao tratamento $\mathrm{CE}_{5}$.

Todos os genótipos de caupi apresentaram reduções, estatisticamente significativas, na produção de matéria seca, em função do aumento da salinidade do solo, explicadas por modelo linear ou quadrático. Silveira et al. (1999) também constataram que o tratamento de plantas de caupi com $100 \mathrm{mM}$ de $\mathrm{NaCl}$ na solução nutritiva ocasionou redução no acúmulo de matéria seca da parte aérea e na relação parte aérea/raiz. Gonzales et al. (2000) estudando o efeito de níveis crescentes de condutividade elétrica na solução nutritiva $(0,3,6,9,12$ e $15 \mathrm{dS} \mathrm{m}^{-1}$ ) sobre o crescimento de 11 cultivares de caupi durante o estádio inicial de crescimento, constataram que os índices de crescimento (altura, comprimento radicular e peso de matéria seca das plântulas) decresceram a medida em que a conduti- 
vidade elétrica na solução aumentou, tendo as cultivares diferido quanto ao grau de tolerância ao estresse salino.

A redução da biomassa de caupi, quando submetido a estresse salino, tem respaldo científico em diversos trabalhos que referenciam que o teor relativo de água nas folhas de plantas de caupi sob salinidade permanece quase inalterado, indicando um eficiente mecanismo protetor acoplado ao fechamento dos estômatos (Costa, 1999). Este fenômeno, que previne as perdas de água pela redução da transpiração e, ao mesmo tempo, mantém o teor relativo de água a nível similar ao das plantas sob condições não salinas (Ferrario et al., 1998; Foyer et al., 1998) ocorre às expensas do suprimento de $\mathrm{CO}_{2}$ para a fotossíntese, diminuindo a produção de biomassa. A salinidade também causa decréscimo na atividade da enzima

Tabela 4. Redução na produção de matéria seca da parte aérea (\%) de genótipos de caupi, em função do aumento da salinidade do solo

\begin{tabular}{|c|c|c|c|c|c|c|c|}
\hline \multirow{2}{*}{ Genótipos } & \multirow{2}{*}{ Equação } & \multirow{2}{*}{$\mathrm{R}^{2}$} & \multirow{2}{*}{$\begin{array}{l}\text { CV } \\
(\%)\end{array}$} & \multicolumn{4}{|c|}{ Redução em Relação ao Controle (\%) } \\
\hline & & & & $\mathrm{CE}_{2}$ & $\mathrm{CE}_{3}$ & $\mathrm{CE}_{4}$ & $\mathrm{CE}_{5}$ \\
\hline Parambu & $Y=21,97158-0,4974396 X-0,112964 X^{2}(*)$ & 0,87 & 24,58 & $6,17^{\mathrm{T}}$ & $10,43^{\mathrm{T}}$ & $85,58^{\mathrm{S}}$ & $91,71^{\mathrm{S}}$ \\
\hline IPA 201 & $\mathrm{Y}=11,9216-0,212644 \mathrm{X}-0,0689864 \mathrm{X}^{2}(* *)$ & 0,95 & 20,59 & $0,62^{\mathrm{T}}$ & $20,03^{\mathrm{T}}$ & $76,82^{\mathrm{S}}$ & $98,48^{\mathrm{S}}$ \\
\hline EPACE 10 & $Y=9,912421-0,27112 X-0,0442618 X^{2}\left(^{*}\right)$ & 0,92 & 17,26 & $3,55^{\mathrm{T}}$ & $17,76^{\mathrm{T}}$ & $77,44^{\mathrm{S}}$ & $89,55^{\mathrm{S}}$ \\
\hline TE 97-303 G5 & $\mathrm{Y}=8,976426-0,5994102 \mathrm{X}(* *)$ & 1,00 & 26,31 & $18,40^{\mathrm{T}}$ & $38,84^{\mathrm{MT}}$ & $59,28^{\mathrm{MS}}$ & $79,73^{\mathrm{S}}$ \\
\hline Cabecinha & $\mathrm{Y}=11,34904-0,8481916 \mathrm{X}(* *)$ & 0,91 & 13,96 & $14,90^{\mathrm{T}}$ & $27,13^{\mathrm{MT}}$ & $81,54^{\mathrm{S}}$ & $83,92^{\mathrm{S}}$ \\
\hline IPA 204 & $Y=9,66461-0,110119 X-0,0592633 X^{2}(* *)$ & 0,99 & 16,42 & $0,13^{\mathrm{T}}$ & $25,52^{\mathrm{MT}}$ & $64,86^{\mathrm{S}}$ & $99,04^{\mathrm{S}}$ \\
\hline TE $97-303$ G6 & $\mathrm{Y}=9,005864-0,6177994 \mathrm{X}(* *)$ & 0,93 & 17,56 & $0,64^{\mathrm{T}}$ & $33,18^{\mathrm{MT}}$ & $70,56^{\mathrm{S}}$ & $75,25^{\mathrm{S}}$ \\
\hline TE-299 G22 & $Y=9,456327-0,7313246 X(* *)$ & 0,95 & 22,31 & $7,68^{\mathrm{T}}$ & $26,55^{\mathrm{MT}}$ & $73,48^{\mathrm{S}}$ & $94,19^{\mathrm{S}}$ \\
\hline TE-299 G16 & $Y=9,389298-0,7124254 X(* *)$ & 0,94 & 21,45 & $1,60^{\mathrm{T}}$ & $34,31^{\mathrm{MT}}$ & $76,58^{\mathrm{S}}$ & $86,41^{\mathrm{S}}$ \\
\hline TE-299 G26 & $\mathrm{Y}=10,02626-0,7777651 \mathrm{X}(* *)$ & 0,93 & 19,86 & $7,15^{\mathrm{T}}$ & $33,34^{\mathrm{MT}}$ & $82,44^{\mathrm{S}}$ & $86,89^{\mathrm{S}}$ \\
\hline Corujinha & $\mathrm{Y}=12,85447-0,9513149 \mathrm{X}(* *)$ & 0,97 & 17,79 & $7,00^{\mathrm{T}}$ & $34,23^{\mathrm{MT}}$ & $70,38^{\mathrm{S}}$ & $86,90^{\mathrm{S}}$ \\
\hline Diamante & $\mathrm{Y}=11,90469-0,8700805 \mathrm{X}(* *)$ & 0,92 & 19,20 & $13,23^{\mathrm{T}}$ & $29,11^{\mathrm{MT}}$ & $79,40^{\mathrm{S}}$ & $81,26^{\mathrm{S}}$ \\
\hline Canapu & $\mathrm{Y}=7,988293-0,6386622 \mathrm{X}(* *)$ & 0,95 & 11,15 & $0,49^{\mathrm{T}}$ & $42,45^{\mathrm{MS}}$ & $76,55^{\mathrm{S}}$ & $92,73^{\mathrm{S}}$ \\
\hline TE 97-309 G3 & $Y=9,457065-0,7510009 X(* *)$ & 0,92 & 14,86 & $2,07^{\mathrm{T}}$ & $41,22^{\mathrm{MS}}$ & $83,70^{\mathrm{S}}$ & $87,37^{\mathrm{S}}$ \\
\hline Galanjão Vermelho & $\mathrm{Y}=30,09895-2,558160 \mathrm{X}(* *)$ & 0,92 & 42,15 & $2,82^{\mathrm{T}}$ & $41,02^{\mathrm{MS}}$ & $92,18^{\mathrm{S}}$ & $94,01^{\mathrm{S}}$ \\
\hline TE 97-367 G4-2 & $\mathrm{Y}=13,07513-1,047299 \mathrm{X}(* *)$ & 0,93 & 14,89 & $0,04^{\mathrm{T}}$ & $45,70^{\mathrm{MS}}$ & $81,95^{\mathrm{S}}$ & $88,53^{\mathrm{S}}$ \\
\hline TE 97-299 G27 & $Y=8,590402-0,6792742 X(* *)$ & 0,95 & 9,17 & $1,82^{\mathrm{T}}$ & $47,22^{\mathrm{MS}}$ & $74,36^{\mathrm{S}}$ & $90,90^{\mathrm{S}}$ \\
\hline Costela de Vaca & $Y=10,49188-0,8734943 X(* *)$ & 0,95 & 19,05 & $6,27^{\mathrm{T}}$ & $46,10^{\mathrm{MS}}$ & $84,56^{\mathrm{S}}$ & $93,65^{\mathrm{S}}$ \\
\hline Ligeirinho & $Y=9,908046-0,8148591 X(* *)$ & 0,94 & 22,40 & $11,20^{\mathrm{T}}$ & $41,29^{\mathrm{MS}}$ & $87,56^{\mathrm{S}}$ & $91,16^{\mathrm{S}}$ \\
\hline TE-430 G13 & $Y=9,504231-0,804576 X(* *)$ & 0,93 & 30,07 & $5,52^{\mathrm{T}}$ & $49,64^{\mathrm{MS}}$ & $89,25^{\mathrm{S}}$ & $92,38^{\mathrm{S}}$ \\
\hline TE 97-304 G4 & $Y=9,938828-0,7908132 X(* *)$ & 0,94 & 16,67 & $5,20^{\mathrm{T}}$ & $50,23^{\mathrm{MS}}$ & $79,06^{\mathrm{S}}$ & $88,14^{\mathrm{S}}$ \\
\hline TE $97-319$ G9 & $\mathrm{Y}=12,59339-0,9817478 \mathrm{X}(* *)$ & 0,92 & 22,20 & $4,42^{\mathrm{T}}$ & $53,99^{\mathrm{MS}}$ & $77,57^{\mathrm{s}}$ & $84,63^{\mathrm{s}}$ \\
\hline IPA 202 & $Y=10,85932-0,8705974 X(* *)$ & 0,99 & 16,03 & $16,84^{\mathrm{T}}$ & $41,59^{\mathrm{MS}}$ & $71,61^{\mathrm{s}}$ & $97,39^{\mathrm{S}}$ \\
\hline TE 97-304 G1 & $\mathrm{Y}=8,230509-0,6238464 \mathrm{X}(* *)$ & 0,96 & 12,02 & $17,61^{\mathrm{T}}$ & $41,55^{\mathrm{MS}}$ & $79,33^{\mathrm{S}}$ & $83,64^{\mathrm{S}}$ \\
\hline TE 97-304 G7 & $\mathrm{Y}=8,436428-0,6522984 \mathrm{X}(* *)$ & 1,00 & 16,70 & $21,37^{\mathrm{MT}}$ & $45,12^{\mathrm{MS}}$ & $68,87^{\mathrm{S}}$ & $92,61^{\mathrm{S}}$ \\
\hline TE 97-299 G13 & $\mathrm{Y}=10,43147-0,7913319 \mathrm{X}(* *)$ & 0,97 & 13,96 & $31,14^{\mathrm{MT}}$ & $42,53^{\mathrm{MS}}$ & $76,36^{\mathrm{S}}$ & $86,42^{\mathrm{S}}$ \\
\hline Canapu Amarelo & $\mathrm{Y}=9,671916-0,8268838 \mathrm{X}(* *)$ & 0,98 & 39,50 & $24,22^{\mathrm{MT}}$ & $51,72^{\mathrm{MS}}$ & $86,49^{\mathrm{S}}$ & $95,32^{\mathrm{S}}$ \\
\hline TE $97-433$ G4 & $\mathrm{Y}=12,28659-1,060080 \mathrm{X}(* *)$ & 0,97 & 32,55 & $25,16^{\mathrm{MT}}$ & $57,68^{\mathrm{MS}}$ & $86,40^{\mathrm{S}}$ & $94,93^{\mathrm{S}}$ \\
\hline IPA 206 & $Y=7,533532-0,96175 X+0,0281882 X^{2}(*)$ & 0,97 & 22,88 & $30,27^{\mathrm{MT}}$ & $53,51^{\mathrm{MS}}$ & $94,31^{\mathrm{S}}$ & $95,22^{\mathrm{S}}$ \\
\hline TE 97-432 G4 & $\mathrm{Y}=8,745745-0,7016080 \mathrm{X}(* *)$ & 0,92 & 47,94 & $38,29^{\mathrm{MT}}$ & $47,79^{\mathrm{MS}}$ & $86,51^{\mathrm{s}}$ & $86,77^{\mathrm{S}}$ \\
\hline TE 97-299 G12 & $Y=7,317470-0,5164967 X(* *)$ & 0,91 & 46,50 & $38,03^{\mathrm{MT}}$ & $48,89^{\mathrm{MS}}$ & $74,91^{\mathrm{S}}$ & $76,85^{\mathrm{S}}$ \\
\hline BR 17 (Gurguéia) & $\mathrm{Y}=12,70354-1,104710 \mathrm{X}(* *)$ & 0,98 & 20,95 & $33,14^{\mathrm{MT}}$ & $53,90^{\mathrm{MS}}$ & $86,27^{\mathrm{S}}$ & $97,56^{\mathrm{S}}$ \\
\hline TE $97-433$ G5 & $Y=18,2583-2,55641 \mathrm{X}+0,0918408 \mathrm{X}^{2}(* *)$ & 0,98 & 24,12 & $38,59^{\mathrm{MT}}$ & $56,49^{\mathrm{MS}}$ & $92,01^{\mathrm{S}}$ & $93,10^{\mathrm{S}}$ \\
\hline TE 97-367 G1 & $Y=14,32524-1,94156 X-0,0670444 X^{2}(* *)$ & 0,97 & 21,37 & $20,14^{\mathrm{MT}}$ & $62,30^{\mathrm{S}}$ & $90,42^{\mathrm{S}}$ & $90,68^{\mathrm{S}}$ \\
\hline TE 97-309 G14 & $Y=15,424-2,10184 X+0,0743392 X^{2}(* *)$ & 1,00 & 20,93 & $30,19^{\mathrm{MT}}$ & $62,82^{\mathrm{S}}$ & $84,69^{\mathrm{S}}$ & $92,72^{\mathrm{S}}$ \\
\hline TE $97-433$ G10 & $Y=16,90725-2,320907+0,081259 X^{2}(* *)$ & 0,96 & 17,17 & $46,94^{\mathrm{MS}}$ & $55,60^{\mathrm{MS}}$ & $87,28^{\mathrm{S}}$ & $95,68^{\mathrm{S}}$ \\
\hline TE $97-432$ G5 & $Y=6,34007-0,977858 X+0,044703 X^{2}(* *)$ & 0,97 & 30,54 & $48,49^{\mathrm{MS}}$ & $63,67^{\mathrm{S}}$ & $77,73^{\mathrm{S}}$ & $85,94^{\mathrm{S}}$ \\
\hline
\end{tabular}

*** Significativos em nível de 0,01 e 0,05 de probabilidade, respectivamente.

T-Tolerante; MT-Moderadamente tolerante; MS-Moderadamente sensível; S-Sensível 
Tabela 5. Produção de matéria seca da parte aérea de plantas de caupi sob baixa condição de salinidade do solo $\left(\mathrm{CE}_{1} 0,3 \mathrm{dS} \mathrm{m}^{-1}\right)$ e os valores de salinidade que ocasionam reduções de 10, 25 e $50 \%$

\begin{tabular}{lcccc}
\hline \multirow{4}{*}{$\begin{array}{c}\text { Genótipos } \\
\text { Produção }\end{array}$} & \multicolumn{3}{c}{ Nível de Salinidade $\left(\mathrm{CE} \mathrm{dS} \mathrm{m}{ }^{-1}\right.$} \\
que Confere Redução na Produção
\end{tabular}

Genótipos moderadamente suscetíveis em $\mathrm{CE}_{3} 6,0 \mathrm{dS} \mathrm{m}^{-1}$

$\begin{array}{lcccc}\text { Canapu } & 7,16 & 2,43 & 4,11 & 6,91 \\ \text { TE 97-309 G3 } & 8,59 & 2,30 & 4,02 & 6,88 \\ \text { Galanjão vermelho } & 27,03 & 2,26 & 3,84 & 6,48 \\ \text { TE 97-367 G4-2 } & 11,86 & 2,30 & 3,99 & 6,82 \\ \text { TE 97-299 G27 } & 7,83 & 2,27 & 4,00 & 6,88 \\ \text { Costela de vaca } & 9,65 & 2,07 & 3,73 & 6,49 \\ \text { Ligeirinho } & 9,25 & 1,95 & 3,65 & 6,49 \\ \text { TE-430 G13 } & 8,79 & 1,98 & 3,62 & 6,35 \\ \text { TE 97-304 G4 } & 9,28 & 2,01 & 3,77 & 6,70 \\ \text { TE 97-319 G9 } & 11,89 & 1,93 & 3,74 & 6,77 \\ \text { IPA 202 } & 10,24 & 1,88 & 3,65 & 6,59 \\ \text { TE 97-304 G1 } & 8,01 & 1,64 & 3,57 & 6,78 \\ \text { Sempre verde } & 8,40 & 1,68 & 3,54 & 6,65 \\ \text { TE 97-299 G3 } & 9,63 & 1,75 & 3,45 & 6,27 \\ \text { TE 97-319 G3 } & 11,26 & 1,78 & 3,54 & 6,46 \\ \text { Flor branca } & 11,60 & 1,61 & 3,42 & 6,44 \\ \text { TE 97-304 G6 } & 9,70 & 1,69 & 3,56 & 6,68 \\ \text { Manteiga } & 9,70 & 1,67 & 3,36 & 6,17 \\ \text { TE 97-365 G3 } & 12,88 & 1,35 & 3,12 & 6,07 \\ \text { TE 97-304 G2 } & 10,86 & 1,56 & 3,47 & 6,64 \\ \text { TE 97-304 G7 } & 8,24 & 1,56 & 3,46 & 6,62 \\ \text { TE 97-299 G13 } & 10,69 & 1,02 & 3,05 & 6,43 \\ \text { Canapu amarelo } & 9,62 & 1,23 & 2,97 & 5,88 \\ \text { TE 97-433 G4 } & 12,43 & 1,04 & 2,80 & 5,73 \\ \text { IPA 206 } & 7,12 & 1,21 & 2,46 & 4,81 \\ \text { TE 97-432 G4 } & 9,34 & 0,49 & 2,48 & 5,81 \\ \text { TE 97-299 G12 } & 8,01 & 0,21 & 2,53 & 6,41 \\ \text { BR 17 (Gurguéia) } & 13,11 & 0,82 & 2,60 & 5,56 \\ \text { TE 97-433 G5 } & 17,58 & 0,99 & 2,15 & 4,40 \\ \text { TE 97-433 G10 } & 16,86 & 0,77 & 1,97 & 4,30\end{array}$

Genótipos suscetíveis em $\mathrm{CE}_{3} 6,0 \mathrm{dS} \mathrm{m}^{-1}$

\begin{tabular}{lcrrr} 
TE $97-367$ G1 & 13,07 & 1,26 & 2,17 & 3,57 \\
TE 97-309 G14 & 14,60 & 1,13 & 2,32 & 4,62 \\
TE 97-432 G5 & 6,31 & 0,70 & 1,79 & 3,98 \\
\hline
\end{tabular}

nitrato redutase foliar e na absorção de nitrato (Costa, 1999) limitando, também, a produção de matéria seca da parte aérea das plantas de caupi, conforme constatado nos presentes experimentos.

Os altos coeficientes de determinação $\left(\mathrm{R}^{2}\right)$ observados em todos os genótipos de caupi, submetidos a níveis crescentes de salinidade no solo, indicam a grande influência que o estresse salino exerce sobre o teor de proteína dos grãos, conforme constatado também por Lemos (1991) para as variedades IPA 202 e CNX 153-3f.

A Tabela 5, mostra a produção de matéria seca da parte aérea de plantas de caupi sob baixa salinidade do solo e os valores de salinidade que ocasionam redução de 10, 25 e 50\%.

Os resultados referentes ao teor de proteína dos grãos de 14 genótipos de caupi submetidos a níveis crescentes de salinidade do solo, encontram-se na Tabela 6.

Os genótipos que apresentaram reduções significativas no teor de proteínas dos seus grãos, explicadas por modelos lineares, foram: IPA 201, IPA 202, Sempre Verde, Cabecinha, TE 97-299 G13 e Canapu Amarelo. A salinidade do solo ocasiona redução no nível de proteínas das plantas, e tanto as proteínas estruturais como as enzimas são afetadas. Esta redução pode ocasionar tanto um retardamento na síntese como uma aceleração na degradação.

Um estudo recente desenvolvido por Silveira et al. (2001) demonstrou que a taxa de absorção de nitrato diminuiu em plantas de caupi desenvolvidas em meio salino; no entanto, não houve alteração da redução deste ânion (atividade da enzima nitrato redutase) sugerindo uma resposta adaptativa a esta condição adversa. Por outro lado, a atividade da enzima sintetase da glutamina e as concentrações de aminoácidos livres e prolina nas folhas, mostraram ligeiro aumento, porém as proteínas solúveis foram ligeiramente reduzidas.

O genótipo TE 97-299 G13, considerado moderadamente

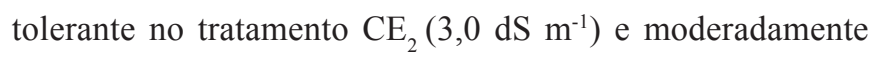
sensível em $\mathrm{CE}_{3}\left(6,0 \mathrm{dS} \mathrm{m} \mathrm{m}^{-1}\right)$, em relação ao peso de matéria seca da parte aérea, foi o que menos alterou o teor de proteína das sementes com o aumento do nível de salinidade do solo, demonstrando ser o genótipo que mais resiste a esta condição adversa, no que diz respeito ao valor nutricional.

O genótipo Canapu Amarelo foi o que mais sofreu redução no teor de proteína dos grãos, porém o seu $\mathrm{R}^{2}$ (coeficiente de determinação) foi de apenas de 0,78.

O genótipo IPA 201 foi o único que apresentou elevado $\mathrm{R}^{2}$, mostrando ser o que melhor responde às variações nos níveis de salinidade do solo, com relação ao teor de proteína dos grãos (Tabela 6).

Esses resultados revelam que o teor de proteína dos grãos de caupi em função da salinidade do solo independe da tolerância do genótipo à salinidade na fase de crescimento. 
Tabela 6. Teor de proteína (\%) nos grãos de genótipos de caupi e redução desta variável em função do aumento da salinidade do solo

\begin{tabular}{|c|c|c|c|c|c|c|c|c|}
\hline \multirow{2}{*}{ Genótipos } & \multirow{2}{*}{$\begin{array}{c}\text { Teor de } \\
\text { Proteína }(\%)\end{array}$} & \multirow{2}{*}{$\begin{array}{l}\text { CV } \\
(\%)\end{array}$} & \multirow{2}{*}{ Equação } & \multirow{2}{*}{$\mathrm{R}^{2}$} & \multicolumn{4}{|c|}{ Redução Percentual em Relação ao Controle (\%) } \\
\hline & & & & & $\mathrm{CE}_{2}$ & $\mathrm{CE}_{3}$ & $\mathrm{CE}_{4}$ & $\mathrm{CE}_{5}$ \\
\hline IPA 201 & 26,07 & 52,58 & $\mathrm{Y}=27,25934-1,319281 \mathrm{X}(*)$ & 0,91 & 0,75 & 30,63 & 49,07 & 50,08 \\
\hline EPACE 10 & 23,07 & 25,42 & $\mathrm{Y}=23,72883-0,1247242 \mathrm{X}(\mathrm{ns})$ & 0,06 & 2,08 & 0,00 & 0,00 & 15,16 \\
\hline TE 97-304 G3 & 25,68 & 31,82 & $\mathrm{Y}=26,29487-0,5949452 \mathrm{X}(\mathrm{ns})$ & 0,75 & 6,91 & 1,36 & 24,95 & 24,95 \\
\hline TE-299 G22 & 23,34 & 24,38 & $\mathrm{Y}=24,64454-0,3500069 \mathrm{X}(\mathrm{ns})$ & 0,42 & 0,00 & 0,00 & 0,00 & 22,68 \\
\hline TE-299 G26 & 25,96 & 4,66 & $\mathrm{Y}=25,21172+0,03915487 \mathrm{X}(\mathrm{ns})$ & 0,04 & 7,24 & 2,36 & 0,00 & 2,85 \\
\hline IPA 205 & 21,72 & 44,57 & $\mathrm{Y}=25,37221-0,8282525 \mathrm{X}(\mathrm{ns})$ & 0,58 & 0,00 & 0,00 & 10,25 & 44,59 \\
\hline Canapu & 25,25 & 30,72 & $\mathrm{Y}=27,25978-0,7479011 \mathrm{X}(\mathrm{ns})$ & 0,42 & 4,21 & 2,90 & 0,00 & 47,69 \\
\hline IPA 202 & 25,59 & 40,27 & $\mathrm{Y}=29,28346-1,460307 \mathrm{X}(* *)$ & 0,74 & 2,55 & 1,53 & 24,27 & 72,39 \\
\hline Sempre Verde & 23,53 & 47,10 & $Y=26,51594-1,300402 X(*)$ & 0,74 & 1,46 & 12,45 & 17,47 & 72,68 \\
\hline TE 97-304 G7 & 28,38 & 35,76 & $Y=29,18955-0,9040504 X(n s)$ & 0,94 & 6,48 & 10,75 & 30,05 & 34,95 \\
\hline Cabecinha & 24,13 & 41,78 & $\mathrm{Y}=26,77802-1,390598 \mathrm{X}(* *)$ & 0,79 & 4,81 & 17,13 & 22,11 & 75,62 \\
\hline TE 97-299 G13 & 22,64 & 2,84 & $\mathrm{Y}=22,45537+0,1094279 \mathrm{X}(* *)$ & 0,37 & 0,29 & 0,00 & 1,05 & 0,00 \\
\hline Canapu Amarelo & 24,21 & 47,61 & $\mathrm{Y}=27,44119-1,825361 \mathrm{X}(* *)$ & 0,78 & 7,24 & 26,74 & 27,77 & 100,00 \\
\hline TE 97-299 G12 & 22,72 & 3,65 & $\mathrm{Y}=23,23887+0,002909034 \mathrm{X}(\mathrm{ns})$ & 0,01 & 0,00 & 0,00 & 0,00 & 0,00 \\
\hline
\end{tabular}

**,*- Significativos em nível de 0,01 e 0,05 de probabilidade, respectivamente; ns - não significativo

\section{CONCLUSÕES}

1. Os genótipos Parambu, IPA 201 e EPACE 10 foram os únicos que desenvolveram mecanismos de tolerância aos níveis de 3,0 e $6,0 \mathrm{dS} \mathrm{m}^{-1}$ de salinidade do solo, podendo ser utilizados como testemunhas em pesquisas futuras.

2. O genótipo TE 97-303 G5 apresentou sensibilidade moderada ao nível de $9,0 \mathrm{dS} \mathrm{m}^{-1}$ de salinidade do solo.

3. Os genótipos TE 97-367 G1, TE 97-309 G14 e TE 97-432 G5 apresentaram sensibilidade ao nível de $6,0 \mathrm{dS} \mathrm{m}^{-1}$ de salinidade do solo podendo, também, ser utilizados como testemunhas em pesquisas futuras.

4. O nível de salinidade $6,0 \mathrm{dS} \mathrm{m}^{-1}$ mostrou-se o mais apropriado para se fazer avaliação de genótipos de caupi para tolerância ao estresse salino.

5. Todos os genótipos de caupi apresentaram reduções estatisticamente significativas na produção de matéria seca, em função do aumento da salinidade do solo.

6. Independente do nível de tolerância na fase de crescimento, os genótipos que apresentaram reduções significativas de proteína nos grãos, foram: IPA 201, IPA 202, Sempre Verde, Cabecinha e Canapu Amarelo.

7. O genótipo TE 97-299 G13 foi o que apresentou menor alteração no teor de proteína dos grãos, com o aumento do nível de salinidade do solo.

\section{LITERATURA CITADA}

Araújo, C.A. de S. Avaliação de feijoeiros quanto a tolerância à salinidade em solução nutritiva. Viçosa: UFV, 1994. 87p. Dissertação Mestrado

Araújo, J.P.P.; Watt, E.E. O caupi no Brasil. 1.ed. Brasília: EITA/ EMBRAPA, 1988. 722p.

Ayers, R.S.; Westcot, D.W. A qualidade da água na irrigação. Campina Grande: UFPB, 1991. 218p. Estudos FAO: Irrigação e Drenagem, 29, Revisado

Costa, R.C.L. Assimilação de nitrogênio e ajustamento osmótico em plantas noduladas de feijão-de-corda, submetidas ao estresse hídrico. Fortaleza: UFC, 1999. 225p. Tese Doutorado
EMBRAPA - Empresa Brasileira de Pesquisa Agropecuária. Manual de métodos de análises de solo. 2.ed. Rio de Janeiro: Centro Nacional de Pesquisa de Solo, 1997. 212p.

Fageria, N.K. Salt tolerance of rice cultivars. Plant and Soil, Dordecht, v.88, n.2, p.237-243, 1985.

Ferrario, S.; Valadier, M.; Foyer, C.H. Over-expression of nitrate reductase in tobaco delays drought-induced decreases in nitrate reductase activity and mRNA. Plant Physiology, Rockville, v.117, p.293-302, 1998.

Foyer, C.H.; Valadier, M.; Migge, A.; Becker, T.W. Droughtinduced effects on nitrate reductase activity and mRNA and on coordination of nitrogen and carbon in maize leaves. Plant Physiology, Rockville, v.117, p.283-292, 1998.

Gheyi, H.R.; Medeiros, J.F. de; Batista, M.A.F. Prevenção, manejo e recuperação de solos salinos e sódicos. Mossoró: ESAM, 1991.70p.

Gonzales, L.M.; Zamora, A.; Cespedes, N. Salt tolerance of cultivars of Vigna unguiculata (L.) Walp during the initial growth stages of plants. Alimentaria, Madrid, v.37, n.314, p.105-108, 2000.

Lemos, G.B. Avaliação do estado nutricional de duas variedades de Caupi (Vigna unguiculata (L.) Walp) submetidas a diferentes níveis de salinidade. Areia: UFPB, 1991. 85p. Monografia Graduação

Malavolta, E.; Vitti, G.C.; Oliveira, S.A. Avaliação do estado nutricional das plantas - Princípios e aplicações. Piracicaba: Potafos, 1989.210p.

Pereira, J.R.; Valdiviesco, C.R.; Cordeiro, G.G. Recuperação de solos afetados por sódio através do uso de gesso. In: Seminário sobre o uso de fosfogesso na agricultura, 1, 1985, Brasília. Resumos...Brasília, 1985.p.85-105.

Santos, D.R.; Stamford, N.P.; Santos, C.E.R.S. Inoculação do caupi em solo salinizado da região semi-árida do Nordeste do Brasil. Revista Brasileira de Ciência do Solo, Campinas, v.14, p.291-295, 1990.

Silveira, J.A.G. da; Cardoso, B. de B.; Melo, A.R.B. de; Viégas, R.A. Salt-induced decrease in nitrate uptake and assimilation in cowpea plants. Revista Brasileira de Fisiologia Vegetal, Londrina, v.11, n.2, p.77-82, 1999.

Silveira, J.A.G.; Melo, A.R.B.; Viégas, R.A.; Oliveira, J.T.A. Salinity-induced effects on nitrogen assimilation related to growth in cowpea plants. Environmental and Experimental Botany, Oxford, v.46, n.2, p.171-179, 2001. 